\title{
A Study of Chemical Composition of Gall Stones in a Tertiary Care Hospital
}

\author{
Bharat Nair ${ }^{1}$ Kunal Malhotra², Ashok Kumar Kaundal³, Anil Malhotra4 \\ 1Department of Surgery, Indira Gandhi Medical College and Hospital, Shimla, Himachal Pradesh, India. \\ ${ }^{2}$ Department of Surgery, Indira Gandhi Medical College and Hospital, Shimla, Himachal Pradesh, India. \\ ${ }^{3}$ Department of Surgery, Indira Gandhi Medical College and Hospital, Shimla, Himachal Pradesh, India. \\ ${ }^{4}$ Department of Surgery, Indira Gandhi Medical College and Hospital, Shimla, Himachal Pradesh, India.
}

\section{ABSTRACT}

\section{BACKGROUND}

Gallstones are a major health problem \& have been recognized since antiquity. Gallstones are generally classified into pure cholesterol, pigment and mixed type. Knowing the chemical composition of gallstones is essential for determining etiopathogenesis of gallstone disease. Fourier Transform Infrared Spectroscopy (FTIR) method is the most widely used technique in chemical analysis of gall stones. Reports on chemical analysis of gallstones are available from different endemic regions of India. However, no reports are available about the composition and etiopathogenesis of gallstones in Himachal Pradesh.

\section{METHODS}

Gallstones from 400 patients of cholelithiasis were collected after cholecystectomy at Indira Gandhi Medical College Hospital (I.G.M.C.), Shimla, between June 2016 to June 2018, and were subjected to chemical analysis by FTIR method. The data was further correlated with regard to age, gender, socio-economic status, various life style factors like diet, obesity, physical activity, with stone number and colour.

\section{RESULTS}

Chemical analysis of gall stones revealed that pure cholesterol, mixed and pigment variety were $94 \%, 2 \%$ and $4 \%$ respectively. Majority of the patients were below the age of 50 years (66\%). Male to female ratio was 2.7:1. Both sexes had predominantly pure cholesterol stones. Most of the patients belonged to the lower middle class (56.5 $\%)$ \& all socio-economic classes showed predominantly pure cholesterol stones. Similarly, there was no predilection of any type of stone to a particular physical work category. $53.5 \%$ patients were non-vegetarians and $46.5 \%$ were vegetarians. There was no correlation between diet and BMI with type of stones. In our study, $66 \%$ of patients had multiple stones. Multiple stones were seen in all varieties of stones. Pure cholesterol stones showed a variety of colours contrary to traditional classification.

\section{CONCLUSIONS}

In Himalayan population, the predominant type of gall stones were pure cholesterol stones. Mixed stones and pigment containing stones were found in much smaller frequencies. This result is in contrast to that of rest of the Indian subcontinent from where larger percentage of pigment and mixed stones has been reported. And pure cholesterol stones showed maximum variation in colours contrary to our expectation.

\section{KEY WORDS}

Gall Stone Disease (GSD), Fourier Transform Infrared (FTIR) Spectroscopy, Chemical Composition, Gall Stones
Corresponding Author: Dr. Kunal Malhotra, Kushal Kunj, Near J.C.B Public School, Sector - 3, New Shimla - 171009, Himachal Pradesh, India E-mail: anilkushalmalhotra@gmail.com

DOI: $10.14260 / j e m d s / 2020 / 527$

How to Cite This Article:

Nair B, Malhotra K, Kaundal AK, et al. A study of chemical copmosition of gall stones in a tertiary care hospital. J Evolution Med Dent Sci 2020;9(34):2422-2426, DOI: 10.14260/jemds/2020/527

Submission 17-05-2020,

Peer Review 14-07-2020,

Acceptance 20-07-2020,

Published 24-08-2020.

Copyright (c) 2020 JEMDS. This is an open access article distributed under Creative Commons Attribution License [Attribution 4.0 International (CC BY 4.0)] 


\section{BACKGROUND}

Gallstones are still a major health problem. Gallstones even have been found in Egyptian mummies dating back to 1000 BC. ${ }^{1}$ Langenbuch performed the first successful cholecystectomy, setting the path for therapeutic intervention. Gallstone is more prevalent in developed nations. ${ }^{2}$ In India, this disease is seven times more common in the North than in South India. Gallstone composition has not attracted adequate attention in current population-based studies leaving uncertainty regarding the confirmation of this assumption. The impact of lifestyle and ethnicity is underscored by the profoundly different gallstone compositions in studies from sub-Saharan Africa, ${ }^{3}$ and China. ${ }^{4}$

Gall stones are generally classified into three major types: pure cholesterol, pigment and mixed gall stones. Pigment gall stones are subdivided into laminated brown stones and amorphous black stones and are more common in Asia and India. In Western countries, about $80 \%$ of gallstones are cholesterol stones, about $15 \%$ to $20 \%$ are black pigment stones, 5 \& brown pigment stones form a small percentage.

In Northern India, pigment and mixed stones are prominent as compared to cholesterol stones \& vegetarian/non-vegetarian diet did not influence the chemical composition. While, South India reported $47 \%$ mixed stones, $41.1 \%$ brown pigment stones and $11.7 \%$ black pigment stones \& no cholesterol stones. ${ }^{5}$

Studies from Saudi Arabia reported low incidence of cholesterol stones. ${ }^{6}$ While study from China, ${ }^{7}$ reported $36.8 \%$ cholesterol stones with variety of colours, $26.9 \%$ pigment stones \& $36.3 \%$ mixed stones \& BMI of patients with cholesterol stones was higher.

Fourier Transform Infra-Red (FTIR) spectroscopy has been established as a means of gallstones analysis by Japanese and US investigators ${ }^{8}$ and mainly used in the large-scale analysis of GS samples. ${ }^{9}$

There is no data available on chemical composition of gallstones from Himachal Pradesh \& our aim was to determine the chemical composition of gall stones and to correlate the chemical composition data with age, gender, diet, physical activity, socio-economic status, stone colour and stone number in this unstudied population having different geographic, environmental and dietary habits.

\section{METHODS}

This was a prospective observational study of gallstones from 400 patients of cholelithiasis which were collected in a single surgical unit of I.G.M.C. Shimla, after cholecystectomy, between June 2016 to June 2018. These were subjected to chemical analysis by Fourier transform infrared spectroscopy (FTIR) method. The data was correlated in relation with age, gender, socio-economic status, diet, obesity, physical activity and with number and colour of stones. After cholecystectomy, stones were removed after sectioning the gall bladder, washed with sterile water and were examined for shape, size and colour. A single gallstone (heaviest one in case of multiple stones) from each patient was subjected to chemical analysis. More than $95 \%$ relative amount of cholesterol was taken as minimum percentage for classifying a stone as pure cholesterol stone. Modified B.G. Prasad scale for socioeconomic status, ${ }^{10}$ revised WHO range for Asia- Pacific region for Body Mass Index \& Worker's Compensation Board of Nova Scotia levels (2014) of physical activity were used.11

\section{Inclusion Criteria}

All patients undergoing cholecystectomy in single surgical unit in I.G. Medical College, Shimla.

\section{Exclusion Criteria}

Patients with: acute cholecystitis, choledocholithiasis, haemolytic anaemias, pregnancy, and liver cirrhosis.

\section{Statistical Analysis}

Statistical correlations between patient age, gender, food habits, physical activity, stone number, stone color and chemical composition of gallstones were performed, using SPSS software version 8.

\section{RESULTS}

In this study, the observed chemical composition was as per table 1 . Age ranged between 10 years to 84 years. Maximum patients were in the age group of 41 - 50 years (26\%) with mean age of 44.07 years and $66.5 \%$ patients were below 50 years. Mean age for pure cholesterol stones was $44.22 \pm 14.11$ years, for mixed stones was $23.25 \pm 2.06$ years and for pigment stones was $50.88 \pm 24.48$ years (Fig. 1). Female patients were $73 \%$, while $27 \%$ were male. Among females, $95.9 \%$ had pure cholesterol stones, $2.7 \%$ had mixed stones and $1.4 \%$ had pigment stones. Among males, $88.9 \%$ had pure cholesterol stones, none had mixed stones and $11.1 \%$ had pigment stones.

In socio-economic status, $56.5 \%$ patients belonged to lower middle class, middle class constituted $18 \%$ of patients, upper middle class constituted $18.5 \%$ of patients, $3 \%$ of patients and upper class constituted $4 \%$ of patients. In all socio-economic classes, cholesterol stones were prominent.

Most patients (67.5\%) with gall bladder stones indulged in mild daily physical activity, $31.5 \%$ patients were involved in moderate daily activity and $1 \%$ indulged in severe/heavy physical activity work. In all categories of physical activity, cholesterol stones were prominent. Regarding diet, $53.5 \%$ patients were non-vegetarian and $46.5 \%$ were vegetarians. Among patients with pure cholesterol stones, $53.7 \%$ were non- vegetarians and $46.3 \%$ were vegetarians. Among patients with mixed stones, $50 \%$ were non vegetarian and 50 $\%$ were vegetarians. Among patients with pigment stones, 50 $\%$ were non vegetarian and $50 \%$ were vegetarians (Fig. 2). In BMI study, $40 \%$ patients belonged to pre-obese/obese category, $41.5 \%$ had normal BMI and $8.5 \%$ were underweight BMI (Fig. 3).

\begin{tabular}{|ccc|}
\hline Type of Stone & Frequency & Percent \\
Cholesterol $>95 \%$ & 376 & 94.0 \\
Bile Salts 75 \%, Cholesterol 25 \% & 8 & 2.0 \\
Cholesterol 30 \% Bile Salts 50 \%, Biliverdin 20 \% & 16 & 4.0 \\
Total & $\mathbf{4 0 0}$ & $\mathbf{1 0 0 . 0}$ \\
\hline Table 1. Number of Gall Bladder Stones Based on Chemical Analysis \\
\hline
\end{tabular}



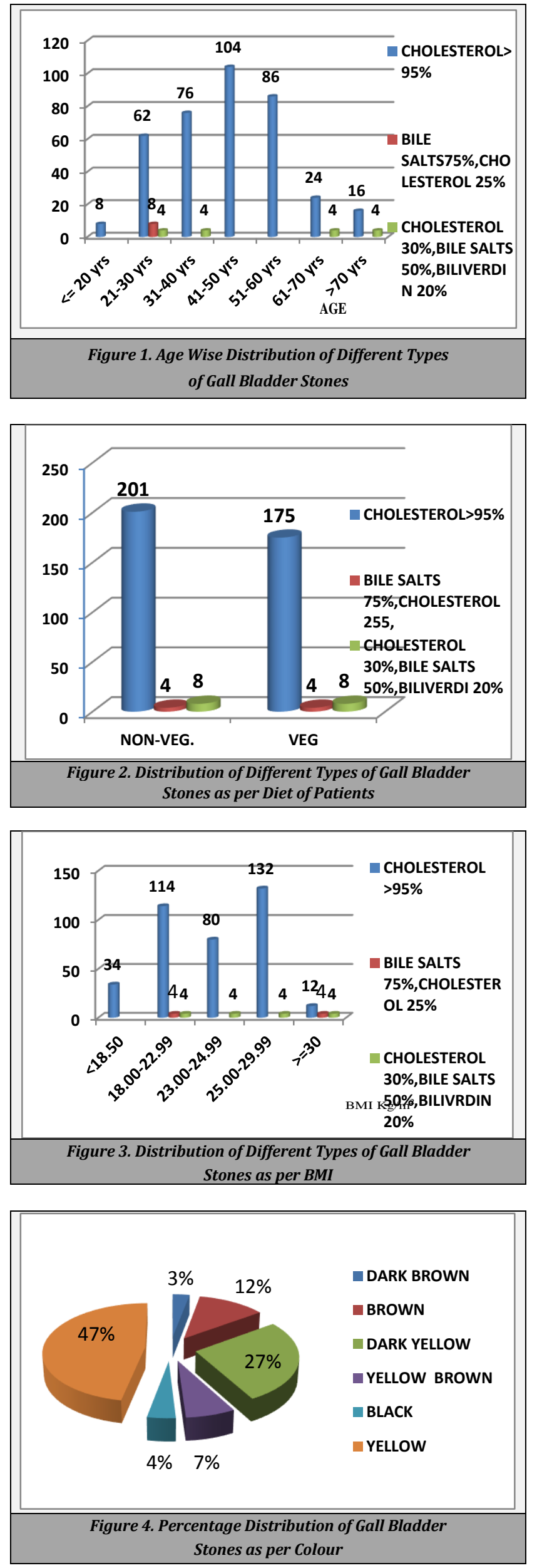

Multiple stones were found in $66 \%$ of patients \& $34 \%$ of patients had single stone. Among pure cholesterol stones, 64.9 $\%$ were multiple and $35.1 \%$ were single $\& 100 \%$ mixed stones were multiple. Among pigment stones, $75 \%$ were multiple and $25 \%$ were single. A variety of stone colours were observed. Pure cholesterol stones showed maximum variety of colour with yellow (50\%), dark yellow (29.3\%), yellow-brown (7.4 $\%)$, brown (12.2\%) and dark brown (1.1\%) stones. None of the pure cholesterol stones was black in colour (Fig. 4). Whereas all mixed stones were dark brown, and all pigment stones were black in colour.

\section{DISCUSSION}

Reports on gallstone disease are mentioned as early as 2000 $\mathrm{BC}$, when the Babylonians first described the bile duct system. The first chemical analysis of the composition of gallstones was made in 1789 by Fourcroy. Surgical treatment of gall stones was established in 1867 by John Bobbs. ${ }^{12}$

Gallstones are common in the Western world, with prevalence rate of $10-15 \%$ for men and about $20 \%$ for women. While prevalence of gallstone disease in India has been reported as $2 \%$ to $29 \%$ \& average age of Indian patients is a decade younger than those in the West. ${ }^{13}$ It is a disorder with increasing life expectancy and changes in life style in "westernised" societies, particularly an increase of cholesterol gallstones. This disease is seven times more common in the North than in South India. Dietary differences in the two regions are suspected to be responsible for this difference. ${ }^{12}$

Gallstones are divided into three major types: cholesterol, black pigment and brown pigment stones. Black pigment stones are common among patients with haemolytic diseases and liver cirrhosis. 14,15 Brown stones are often caused by stasis and infection in the biliary system. In the Western world, the major constituent of gallstones is cholesterol, which comprises $50-98 \%$ of the dried substance of the stone. Other constituents may include fatty acids, triglycerides, proteins, polysaccharides, calcium bilirubinate, calcium carbonate and calcium bicarbonate. Gallbladder stones vary in size from less than a millimetre up to few centimetres in diameter. Thus, application of novel preventive or therapeutic approaches will likely be limited to certain classes of gallstones as defined by their composition and aetiology. 16,17

We used FTIR, in order to define the target populations for future therapeutic and preventive therapies and to investigate the gallstones composition in Himachal Pradesh. As there have been no studies to evaluate the chemical composition of gall stones from the Himalayan region of South East Asia and one has to rely on and extrapolate data related to epidemiology and chemical composition of gall stones which is generalised to Northern plains of India.

In our study, $94 \%$ of the patients had pure cholesterol stones, $2 \%$ of patients had mixed stones and $4 \%$ of patients had pigment stones. Findings of our study are also in consonance with other studies in the Western world which all showed that about $80 \%-90 \%$ of gallstones are cholesterol stones while about $10 \%$ to $20 \%$ are black pigment stones and mixed stones in $0 \%-5 \%$ patients. ${ }^{18,19}$ Brown pigment stones accounts for a small percentage. Both types of pigment stones are more common in Asia as well as in India. ${ }^{19,20}$ 
However, findings of our study are in contrast to studies done in the Indian subcontinent ${ }^{21}$ which reported pigment stones in $36 \%-40 \%$ patients, mixed stones in $35 \%-58 \%$ patients and cholesterol stones in only $25 \%-42 \%$ patients. While studies from South India, ${ }^{22}$ reported $47 \%$ mixed stones, $41.1 \%$ brown pigment stones and $11.7 \%$ black pigment stones. There were no cholesterol stones. Our findings were also not in consonance with studies from the Middle East, Africa and China ${ }^{4}$ which reported $49.3 \%-17 \%$ cholesterol stones, $31.3 \%-36.3 \%$ mixed stones and $17.3 \%-51.07 \%$ pigment stones.

Age and sex distribution of gall stones was found similar to other Indian and International studies 23 , with maximum occurrence in the age group of 41 - 50 years and with a female predominance. This might be due to the basic hormonal differences between males and females. Both sexes showed a predominance of cholesterol stones with $100 \%$ of mixed stones occurring in females. And $75 \%$ of pigment stones occurring in males, this finding is similar to finding of other study, ${ }^{23}$ that there is a correlation between stone types and gender; male patients predominantly tend to develop mixed stones or pigment stones. However, our findings are concurrent with study by Schafmayer et al, ${ }^{13}$ which reported that cholesterol stones were predominant in both sexes, while $58 \%$ of pigment stones were seen in males.

Most of the patients belonged to lower middle class (56.5 $\%)$. Patients belonging to all social classes had predominantly pure cholesterol stones. Our findings were not in consonance with other study that gallstone disease was more frequently seen in high socioeconomic class. Most of the patients $(67.5 \%)$ were involved in mild daily physical activity while $31.5 \%$ patients were involved in moderate daily activity. Patients involved in severe/heavy work were only $1 \%$. All three categories had predominantly pure cholesterol stones. This finding of a negative relation between physical activity and occurrence of gall stones, confirms the findings of previous studies. ${ }^{23}$ There was no correlation between type of diet and gallstones composition. These findings are concurrent with other studies, that vegetarian/non-vegetarian diet did not influence the prevalence and chemical composition of gallstones.

In BMI study, $40 \%$ patients belonged to pre-obese/obese category with $\mathrm{BMI}>=25 \mathrm{Kg} / \mathrm{m}^{2}, 51.5 \%$ had BMI in normal range and $8.5 \%$ had below normal BMI. Pure cholesterol stones were predominant $(>90 \%$ ) in all categories of BMI. Our study showed no correlation between BMI and gallstones. There was also no specific predilection of any type of gallstone to a particular BMI range. These findings are in consonance with study by Singh A et al [24] who reported that body mass index did not influence the prevalence of gallstone disease. Our findings are not in consonance with findings of Schafmayer et $\mathrm{al}^{13}$ who reported that $\mathrm{BMI}>25 \mathrm{Kg} / \mathrm{m}^{2}$, was significantly associated with gallstones predominantly of cholesterol.

In our study, majority (66\%) of patients had multiple stones and $34 \%$ of patients had single stones. Multiple and single stones were seen in all three type of gall stones. These findings are in consonance with findings by Bansal et al ${ }^{24}$ who reported multiple stones in $75 \%$ and single stones in $25 \%$ patients. Pure cholesterol stones showed maximum variation in colour. None of the pure cholesterol stones was black in colour. All mixed stones $(100 \%)$ were dark brown and all pigment stones $(100 \%)$ were black in colour. These findings are in consonance with other studies, ${ }^{25}$ which reported various colours of cholesterol stones as; brownish yellow, amber, grey, celadon or black while pigment stones were amorphous, brittle, granules having black, charcoal grey or greyish brown colour. Other studies, ${ }^{20}$ have classified the stones prior to analysis of chemical composition, as either cholesterol, mixed or pigment, based on colour and later performed the analysis.

Based on our findings, we are of the opinion that, classifications based solely on colour may be misleading giving rise to misreporting of actual occurrence of different types of stones. Classifications must be based on the more accurate and reliable chemical composition reports rather than visual inspection of colour of the stones.

This is possibly the first study to evaluate the chemical composition of gall stones from the Himalayan region of India in South East Asia and compare the same with various epidemiological and life style factors. Studies from Northern India have by and large focussed on chemical composition of gall stones of patients from the plains of North India.

This study showed a predominance of cholesterol stones, which is in consonance with studies done in the Western World showing percentage occurrence of cholesterol stones above 90 \%, more so in European countries with cold climate like Germany and Sweden, 25 where climatic conditions are similar to Himachal Pradesh.

However, our findings were in contrast to other Indian studies from both North India and South India, ${ }^{15,16}$ which have described a higher occurrence of pigment and mixed stones as compared to cholesterol stones. Our findings were also not in consonance with findings from Middle East, China and Africa, 6,7 all of which showed a much lower prevalence of cholesterol stones. Higher occurrence of cholesterol stones in patients from Himachal Pradesh could be related to similar environmental and dietary factors as in Western populations.

\section{CONCLUSIONS}

All patients showed a predominance of cholesterol stones with $100 \%$ of mixed stones occurring in females and $75 \%$ of pigment stones occurring in males. Most of the patients with gall stones belonged to the lower middle socio-economic strata \& maximum number of patients were in mild physical activity group. There was no specific co - relation to diet or BMI with the occurrence of gall stones or with their chemical composition. Most patients had multiple stones and stones showed varying colours with pure cholesterol stones showing maximum variation in colour.

Financial or Other Competing Interests: None.

\section{REFERENCES}

[1] Berci G. Historical overview of surgical treatment of biliary stone disease. In: MacFadyen BV, Arregui M, Eubanks S, et al. eds. Laparoscopic surgery of the abdomen. New York (NY): Springer 2004:139-42. 
[2] Attasaranya S, Fogel EL, Lehman GA. Choledocholithiasis, ascending cholangitis, and gallstone pancreatitis. Med Clin North Am 2008;92(4):925-60.

[3] Rains AJH. Gallstones: causes and treatments. London: William Heinemann Medical Books 1964.

[4] Lu SN, Chang WY, Wang LY, et al. Risk factors for gallstones among Chinese in Taiwan. A community sonographic survey. J Clin Gastroenterol 1990;12(5):5426.

[5] Kern F. Epidemiology and natural history of gallstones. Semin Liver Dis 1983;3(2):87-96.

[6] Alsaif MA. Variations in dietary intake between newly diagnosed gallstone patients and controls. Pakistan J Nut 2005;4(1):1-7.

[7] Chandran P, Kuchhal NK, Garg P, et al. An extended chemical analysis of gallstone. Indian J Clin Biochem 2007;22(2):145-50.

[8] Taher MA. Descriptive study of cholelithiasis with chemical constituents' analysis of Gallstones from patients living in Baghdad, Iraq. I.J.A.B.R 2013;3(1):80-4.

[9] Qiao T, Ma RH, Luo XB, et al. The systematic classification of gallbladder stones. PLoS One 2013;8(10):e74887.

[10] Shaikh Z, Pathak R. Revised Kuppuswamy and B G Prasad socio-economic scales for 2016. Int J Community Med Public Health 2017;4(4):997-9.

[11] https://www.wcb.ns.ca/Health-Services/WorkCapabilities-Definition.aspx

[12] Chihara G, Yamamoto S, Kameda H. Medical and biochemical application of infrared absorption spectra. I. Studies on gallstone by infrared spectra and X-ray crystallography. Chem Pharm Bull (Tokyo) 1958;6(1):504.

[13] Schafmayer C, Hartleb J, Tepel J, et al. Predictors of gallstone composition in 1025 symptomatic gallstones from Northern Germany. BMC Gastroenterol 2006;6:36.
[14] Davis CJ. A history of endoscopic surgery. Surg Laparosc Endosc 1992;2(1):16-23.

[15] Das B, Malik AK, Rehman A, et al. Quantitative analysis of chemical composition of gallstones in North Indian population. Rohilkhand Region, Uttar Pradesh. Natl J Integr Res Med 2014;5(4):4-12.

[16] Raman RG, Selvaraju R. FTIR spectroscopic analysis of human gallstones. Romanian J Biophys 2008;18(4):30916.

[17] Aydogdu I, Sari R, Ulu R, et al. The frequency of gallbladder stones in patients with pernicious anemia. J Surg Res 2001;101(2):120-3.

[18] Benvegnu L, Noventa F, Chemello L, et al. Prevalence and incidence of cholecystolithiasis in cirrhosis and relation to the etiology of liver disease. Digestion 1997;58(3):2938.

[19] Trotman BW, Ostrow JD, Soloway RD. Pigment vs cholesterol cholelithiasis: comparison of stone and bile composition. Am J Dig Dis 1974;19(7):585-90.

[20] Kleiner O, Ramesh J, Huleihel M, et al. A comparative study of gallstones from children and adults using FTIR spectroscopy and fluorescence microscopy. BMC Gastroenterol 2002;2:3.

[21] Bhansali SK. Choledochostomy. Indian J Surg 1979;41:485-91.

[22] Pundir CS, Chaudhary R, Rani K, et al. Chemical analysis of biliary calculi in Haryana. Indian J Surg 2001;63(5):3703.

[23] Singh A, Bagga SP, Jindal VP, et al. Gall bladder disease: an analytic report of 250 cases. J Indian Med Assoc 1989;87(11):253-6.

[24] Bansal SK, Gupta AK, Bansal A, et al. Chemical composition of biliary calculi from Kanpur region. Indian J Clin Biochem 1992;7:27-9.

[25] Kurtin WE, Schwesinger WH, Diehl AK. Age-related changes in the chemical composition of gallstones. Int J Surg Invest 2000;2(4):299-307. 